\title{
PENGARUH SWISS BALL EXERCISE TERHADAP INTENSITAS NYERI DISMENOREA DI SMK NEGERI 1 GEROKGAK
}

\author{
(Swiss Ball Exercise Effect on Intensity of Dysmenorrhoea Pain In SMK Negeri 1 Gerokgak)
}

\author{
Ari Pertama Watiningsih ${ }^{1}$, Made Martini ${ }^{2}$ \\ Program Studi D3 Kebidanan, Sekolah Tinggi Ilmu Kesehatan Buleleng \\ e-mail: arivito_jayapura@yahoo.co.id
}

\begin{abstract}
ABSTRAK
Pendahuluan: Nyeri disminorea adalah suatu rasa nyeri yang dirasakan sebelum atau selama menstruasi, yang menyebabkan ketidakmampuan dalam melakukan aktivitas selama 1-3 hari setiap bulannya, Swiss ball Exercice merupakan latihan dengan metode menggunkan bola karet dengan diameter 45-120 cm yang efektif dalam melatih muskuloskeletal. Tujuan: bertujuan untuk mengetahui pengaruh swiss ball exercise terhadap intensitas nyeri dismenorea di SMK Negeri 1 Gerokgak. Metode: Jenis penelitian ini adalah quasy experiment dengan rancangan pre-posttest with control group design dengan teknik simple random sampling. Tingkat itensitas nyeri di ukur dengan lebar observasi skala nyeri bourbonnais. Hasil: Hasil penelitian menunjukkan rata-rata intensitas nyeri pre test pada kelompok perlakuan adalah 4.92 dan kelompok kontrol 3.96. Setelah diberikan teknik swiss ball exercise di peroleh rata-rata nilai intensitas nyeri pada kelompok perlakuan 3.24 dan kelompok kontrol 4.04. Kesimpulan: Hasil analisis data dengan independent t-test di dapatkan nilai $(0,002)$ atau $<\alpha(0,05)$ yang berarti ada pengaruh swiss ball exercise terhadap intensitas nyeri dismenorea di SMK negeri 1 Gerokgak.
\end{abstract}

Kata kunci: Teknik Swiss Ball Exercise, Nyeri Disminorea

\begin{abstract}
Introduction: Disminorrhea pain is a pain that is felt before or during menstruation, which causes inability to do activities for 1-3 days per month, Swish Ball Exercise is a exercise which uses a rubber ball with 45-120 cm diameters method which effective to train the musculoskeletal. Purpose: determine the effect of swiss ball exercise on the intensity of dysmenorrhoea pain in SMK Negeri 1 Gerokgak. Methods: This type of research is quasy experiment with pre-posttest with control group design, the sample in this reasserch are50 respondents with simple random sampling technique. Results: The results showed that the average of pre test pain intensity in the treatment group was 4.92 and in the control group was 3.96. After the swiss ball exercise technique was obtained the average of pain intensity value in treatment group was 3.24 and in the control group was 4.04 . Conclutions: The results of data analysis with independent t-test in the value obtained (0.002) or $<\alpha(0.05)$ which means there is the influence of swiss ball exercise on the intensity of dysmenorrhoea pain in SMK Negeri 1 Gerokgak.
\end{abstract}

Keyword: Chromotherapy, Hallucinations Level.

\section{PENDAHULUAN}

Dismenorea merupakan keluhan yang dialami perempuan pada bagian perut bawah. Dismenorea berasal dari bahasa Yunani yaitu dis yang berarti menyakitkan atau tidak normal, meo yang berarti bulan, dan rhea yang berarti aliran. Dismenorea tidak hanya terjadi pada bagian perut bawah saja. Beberapa remaja merasa nyeri pada punggung bagian bawah, pinggang dan panggul (Laila, 2011:24). 
Angka kejadian dismenorea didunia rata-rata lebih dari 50\% setiap Negara. Di Negara Indonesia lebih banyak remaja yang mengalami dismenorea yaitu sebanyak $55 \%$. Nyeri dismenorea banyak terjadi di kalangan usia produktif berkisar 45-95\%. Angka kejadian dismenorea primer rata-rata 54,85\% dan sisanya mengalami dismenorea sekunder. Dapat dikatakan sebanyak 90\% remaja di Indonesia pernah mengalami dismenorea. (Anurogo \& Wulandari, 2011:36-37). 
Swiss ball exercise merupakan suatu latihan yang efektif dalam melatih sistem muskuloskeletal dengan sebuah bola yang memiliki manfaat yaitu sebagai fleksibilitas, peningkatan kekuatan, memperbaiki posisi dan keseimbangan otot (Ratmawati, Setiawan \& Kuntono, 2015). Menurut Hooper dalam pramita 2017 peningkatan tekanan intra abdomen akan mendorong kolumna vertebralis kearah belakang, sehingga hiperlordosis lumbal dapat dikurangi dan tekanan pada diskus intervertebralis berkurang yang dapat mengurangi nyeri pada daerah perut dan punggung. (Oktaviani \& Letari, 2017).

Berdasarkan studi pendahuluan yang dilakukan oleh peneliti di SMK Negeri 1 Gerokgak pada tanggal 2 April 2019, didapatkan data siswi SMK Negeri 1 Gerokgak berjumlah kelas X 104 orang. Kemudian data siswi yang mengalami dismenorea sebanyak 60 siswi. Setelah dilakukan wawancara dan observasi dengan 10 orang siswi, terdapat siswi yang menyatakan nyeri 1-3 sebanyak 5, kemudian yang mengalami nyeri 4-5 sebanyak 4 dan siswi yang mengalami nyeri 7-10 sebanyak 1. Pada saat peneliti menanyakan bagaimana cara mengatasi dismenorea kepada siswi, beberapa siswi mengatakan memberikan minyak dan hanya dibiarkan sampai hilang, istirahat di UKS, bahkan ijin pulang sekolah untuk beristirahat.

Berdasarkan uraian pada latar belakang di atas, maka dapat dirumuskan masalah "Bagaimana pengaruh swiss ball exercise terhadap intensitas nyeri dismenorea di SMK Negeri 1 Gerokgak”? 


\section{METODE PENELITIAN}

Penelitian ini mengunakan jenis penelitian Quasy Experiment dengan rancangan Pre-Posttest With Control Group Design. Ciri dari rancangan penelitian ini desain ini yaitu terdapat dua kelompok kelompok perlakuan yang di berikan latihan swiss ball exercise dan kelompok kontrol tidak di berikan perlakuan, akan tapi digunakan sebagai pembanding perbedaan nilai intensitas nyeri. Pada desain ini dilakukan sebanyak dua kali yaitu sebelum experimen dan sesedah experiment (Nursalam, 2015:64).

\section{HASIL}

\section{PENELITIAN}

\section{DAN PEMBAHASAN}

Sampel dalam penelitian ini menggunakan responden yang mengalami nyeri dismenorea di SMK Negeri 1 Gerokgak. Adapun karakteristik sampel penelitian ini adalah sebagai berikut:

Tabel 4.1 Analisis Deskriptif Karakteristik Responden Berdasarkan Umur Kelompok Perlakuan.

\begin{tabular}{cc}
\hline Variabel & Persentase (\%) \\
${$\cline { 1 - 1 }$} }$ & \\
15 Tahun & 20.0 \\
16 Tahun & 72.0 \\
17 Tahun & $\underline{8.0}$ \\
\hline
\end{tabular}

Hasil analisis univariat karakteristik responden pada tabel 4.1 ditemukan bahwa umur responden sebagian besar berumur 16 tahun yaitu sebanyak $72.0 \%$.
Tabel 4.2 Analisis Deskriptif Karakteristik Responden Berdasarkan Umur Kelompok Kontrol.

\begin{tabular}{|c|c|}
\hline Variabel & Persentase (\%) \\
\hline Umur Respoden & \\
\hline 15 Tahun & 36.0 \\
\hline 16 Tahun & 52.0 \\
\hline 17 Tahun & 12.0 \\
\hline
\end{tabular}


Hasil analisis univariat karakteristik responden pada tabel 4.2 ditemukan bahwa umur responden sebagian besar berumur 16 tahun yaitu sebanyak $52.0 \%$.

Tabel 4.3 Skor Intensitas Nyeri Responden Sebelum Diberikan Terapi Swiss Ball Exercise Kelompok Perlakuan

\begin{tabular}{|c|c|c|c|}
\hline $\begin{array}{c}\text { Skor Intensitas } \\
\text { Nyeri } \\
\text { Responden }\end{array}$ & $\begin{array}{l}\text { Rata- } \\
\text { Rata } \\
\text { (mean) }\end{array}$ & $\begin{array}{c}\text { Std. } \\
\text { Deviation }\end{array}$ & $\begin{array}{c}\text { Std. } \\
\text { Error } \\
\text { Mean } \\
\end{array}$ \\
\hline Pre Test & 4.92 & .954 & .191 \\
\hline
\end{tabular}

Berdasarkan tabel 4.3 didapatkan rata-rata intensitas nyeri, sebelum diberikan swiss ball exercise adalah 4.92 dengan Standar Deviation 0.954 dan Standar Error Mean 0.191.

Tabel 4.4 Skor Intensitas Nyeri Responden Sebelum Diberikan Terapi Swiss Ball Exercise Kelompok Kontrol.

\begin{tabular}{cccc}
$\begin{array}{c}\text { Skor Intensitas } \\
\text { Nyeri } \\
\text { Responden }\end{array}$ & $\begin{array}{c}\text { Rata- } \\
\text { Rata } \\
(\text { mean) }\end{array}$ & $\begin{array}{c}\text { Std. } \\
\text { Deviation }\end{array}$ & $\begin{array}{c}\text { Std. } \\
\text { Error } \\
\text { Mean }\end{array}$ \\
\hline Pre Test & 3.96 & .978 & .196 \\
\hline
\end{tabular}

Berdasarkan tabel 4.3 didapatkan rata-rata intensitas nyeri, sebelum diberikan swiss ball exercise adalah 3.69 dengan Standar Deviation 0.978 dan Standar Error Mean 0.196.

Tabel 4.5 Skor Intensitas Nyeri Responden Sesudah Diberikan Terapi Swiss Ball Exercise Kelompok Perlakuan.

\begin{tabular}{|c|c|c|c|}
\hline $\begin{array}{c}\text { Skor Intensitas } \\
\text { Nyeri } \\
\text { Responden }\end{array}$ & $\begin{array}{c}\text { Rata- } \\
\text { Rata } \\
\text { (mean) } \\
\end{array}$ & $\begin{array}{c}\text { Std. } \\
\text { Deviation }\end{array}$ & $\begin{array}{c}\text { Std. } \\
\text { Error } \\
\text { Mean } \\
\end{array}$ \\
\hline Post Test & 3.24 & .779 & .156 \\
\hline
\end{tabular}

Berdasarkan tabel 4.5 didapatkan ratarata intensitas nyeri, sesudah diberikan swiss ball exercise adalah 3.24 dengan Standar Deviation 0.779 dan Standar Error Mean 0.156 .

Tabel 4.6 Skor Intensitas Nyeri Responden
Berdasarkan tabel 4.6 didapatkan rata-rata intensitas nyeri, sesudah diberikan swiss ball exercise adalah 4.04 dengan Standar Deviation 0.935 dan Standar Error Mean 0.187.

Tabel 4.7 Uji Normalitas Skewness Kelompok Perlakuan

\begin{tabular}{cccc}
\hline & & \multicolumn{2}{c}{ Skewness } \\
\hline & & Df & Sig \\
\hline Swiss Ball & Pre test & 25 & -0.982 \\
Exercise & Post test & 25 & 1.480
\end{tabular}

Tabel 4.7 menunjukan bahwa nilai $p$ value pada kelompok swiss ball exercise sebelum intervensi (pre test) adalah -0.982 dan setelah intervensi adalah 1.480. Sehingga $p$ value yang diperoleh dari kelompok $<2$ maka data berdistribusi normal dan uji statistik yang digunakan adalah statistik parametrik dengan uji Paired T-test.

Tabel 4.8 Uji Normalitas Skewness Kelompok Kontrol

Skewness

\begin{tabular}{|c|c|c|c|}
\hline & & Df & Sig \\
\hline Swiss Ball & Pre test & 25 & 1.435 \\
\hline Exercise & Post test & 25 & 0.293 \\
\hline
\end{tabular}

Sesudah Diberikan Terapi Swiss Ball Exercise Kelompok Kontrol.

\begin{tabular}{|c|c|c|c|}
\hline $\begin{array}{c}\text { Skor Intensitas } \\
\text { Nyeri } \\
\text { Responden } \\
\end{array}$ & $\begin{array}{l}\text { Rata- } \\
\text { Rata } \\
\text { (mean) }\end{array}$ & $\begin{array}{c}\text { Std. } \\
\text { Deviation }\end{array}$ & $\begin{array}{c}\text { Std. } \\
\text { Error } \\
\text { Mean }\end{array}$ \\
\hline Post Test & 4.04 & .935 & .187 \\
\hline
\end{tabular}


Tabel 4.8 menunjukan bahwa nilai $p$ value pada kelompok swiss ball exercise sebelum intervensi (pre test) adalah 1.435 dan setelah intervensi adalah 0.293. Sehingga $p$ value yang diperoleh dari kelompok <2 maka data berdistribusi normal dan uji statistik yang digunakan adalah statistik parametrik dengan uji Paired T-test.

Tabel 4.10 Nilai Pre dan Post Test Dengan Uji Paired T-Test Kelompok Kontrol.

\begin{tabular}{|c|c|c|c|c|}
\hline \multirow{2}{*}{$\begin{array}{l}\text { Pemberian } \\
\text { Swiss Ball } \\
\text { Exercise }\end{array}$} & \multirow[t]{2}{*}{ Mean } & \multirow{2}{*}{$\begin{array}{l}\text { Nilai } \\
\mathrm{p}\end{array}$} & \multicolumn{2}{|c|}{$95 \% \mathrm{Cl}$} \\
\hline & & & $\begin{array}{l}\text { Lowe } \\
\mathrm{r}\end{array}$ & $\begin{array}{l}\text { Uppe } \\
\text { r }\end{array}$ \\
\hline $\begin{array}{l}\text { Pre Test } \\
\text { Post Test }\end{array}$ & $\begin{array}{l}3.96 \\
4.04 \\
\end{array}$ & 0,161 & -.194 & .034 \\
\hline
\end{tabular}

Tabel 4.9 diatas menunjukkan bahwa ratarata tingkat intensitas sebelum dan sesudah 
dilakukan pemberian swiss ball exercise pada kelompok kontrol mengalami peningkatan rata-rata dan ini sangat berpengaruh secara signifikan dengan nilai $\mathrm{p}>0,05$ sehingga ditemukan hasil bahwa tidak ada pengaruh yang signifikan dalam mengontrol intensitas nyeri dismenorea pada siswi di SMK Negeri 1 Gerokgak.

Tabel 4.9 Nilai Pre dan Post Test Dengan Uji Paired T-Test Kelompok Perlakuan

\begin{tabular}{ccccc}
\hline Pemberian & Mean & Nilai & \multicolumn{2}{c}{$95 \%$ CI } \\
\cline { 4 - 6 } Swiss Ball & & $\mathrm{p}$ & Lowe & Uppe \\
Exercise & & & $\mathrm{r}$ & $\mathrm{r}$ \\
\hline Pre Test & 4.92 & 0,000 & 1.349 & 2.011 \\
Post Test & $\underline{3.24}$ & & &
\end{tabular}

Tabel 4.9 diatas menunjukkan bahwa rata-rata tingkat intensitas sebelum dan sesudah dilakukan pemberian swiss ball exercise mengalami penurunan rata-rata dan ini sangat berpengaruh secara signifikan dengan nilai $\mathrm{p}<0,05$ sehingga ditemukan hasil bahwa ada pengaruh pemberian swiss ball exercise dalam mengontrol intensitas nyeri dismenorea pada siswi di SMK Negeri 1 Gerokgak.

Tabel 4.11 Analisis Data Nilai Post Perlakuan dan Kontrol Dengan Independen T-test.

\begin{tabular}{ccc}
\hline Jenis Data & Mean & Nilai p \\
\hline $\begin{array}{c}\text { Intensitas nyeri } \\
\text { post kelompok } \\
\text { perlakuan }\end{array}$ & 3.96 & 0.002 \\
$\begin{array}{c}\text { Intensitas nyeri } \\
\text { post kelompok } \\
\text { kontrol }\end{array}$ & 4.04 & \\
\hline Tabel 4.11 didapatkan hasil analisis
\end{tabular}

penurunan intensitas nyeri dismenorea di SMK Negeri 1 Gerokgak.

Dilihat dari karakteristik responden berdasarkan usia pada kelompok perlakuan ditemukan bahwa usia responden yang lebih banyak adalah 16 tahun (72.0\%) dan pada kelompok kontrol usia yang paling banyak adalah usia16 tahun (52.0\%). Berdasarkan hasil penelitian diatas merupakan usia responden dalam golongan remaja akan sering mengalami nyeri dismenorea pada saat menstruasi.

Menurut Proverawati \& Misaroh (2011: 23) yang menyatakan usia perempuan yang mengalami usia menarche dini akan sering mengalami nyeri pada saat menstruasi. Apabila umur perempuan masih muda akan sering merasakan nyeri dismenorea dengan rintang ringan dan sedang. Sebagian besar perempuan yang mengalami nyeri dismenorea pada saat menstruasi akan sering terganggu aktivitas sehari-hari seperti belajar, sekolah, kuliah, bekerja dan aktivitas lainnya. Dismenorea yang terjadi pada remaja tersebut, jika tidak diatasi maka akan mengganggu semua aktivitas terutama aktivitas belajar di kelas.

statistik pada kedua kelompok didapatkan nilai $p$ yaitu 0.002 atau nilai $\mathrm{p}<0,05$. Dapat dikatakan ada pengaruh yang signifikan dalam pemberian terapi swiss ball exercise terhadap 
Dari hasil penelitian menunjukan bahwa rata-rata intensitas nyeri sebelum diberikan terapi swiss ball exercise pada kelompok perlakuan 4.92 dan pada kelompok kontrol adalah 3.96. Setelah diberikan terapi swiss ball exercise, pada kelompok perlakuan terdapat penurunan ratarata 3.24 sedangkan kelompok kontrol terjadinya peningkatan yaitu 4.04. Hal ini Hal ini di sebabkan oleh kondisi yang dipengaruhi oleh beberapa faktor seperti ketidakseimbangan hormonhormon yang 
diproduksi oleh tubuh saat tidak melakukan aktivitas (Anurogo \& Wulandari, 2011:30).

Penelitian yang terkait dengan penelitian dari oleh Ade Kurniawati, Djaswadi, dan Farida Karini dengan judul "Efektivitas Latihan Birth Ball terhadap Penurunan Nyeri Persalinan Kala 1 Fase Aktif Pada Primigravida" di dapatkan hasil sebanyak 38 ibu bersalin yang dibagi menjadi 2 kelompok yaitu 19 ibu bersalin kelompok perlakuan yang diberikan latihan birth ball selama 30 menit dan 19 ibu bersalin kelompok kontrol tidak diberikan latihan birth ball. Hasil penelitian menunjukkan bahwa pada kelompok perlakuansesudah pemberian terapi birth ball yaitu 4.5 dan kelompok kontrol 5.4 dengan nilai rata-rata sebelum diberikan terapi birh ball yaitu 4.9. Dapat di katakan bahwa pemberian terapi bitrh ball merupakan pengobatan non farmakologi yang sangat baik dalam mengurangi intensistas nyeri persalinan kala 1 fase aktif pada primigravida.

Hasil dari penelitian yang dilakukan selama 1 bulan dengan 3 kali seminggu dengan durasi waktu 30 menit. Hal ini didukung dengan penelitian Kodir, Angliadi, dan Lolombulan tahun 2018 dengan judul "Pengaruh Latihan Core Strengthing Menggunkanan Swiss Ball Menurunkan Intensitas Nyeri Dan Meningkatkan Kemampuan Fungsional Nyeri Punggung Bawah Non spesifik Kronik" dengan pemberian terapi swiss ball exercise sebanyak
3 kali seminggu selama 1 bulan dengan hasil analisis $\mathrm{p}=0,0001<0,05$ yang artinya ada pengaruh degan melakukan latihan swiss ball exercise terhadap mengurangi nyeri dengan penurunan rata-rata 3,47 . 
Hasil uji statistik dengan mengunakan uji beda Independent T-Test di dapatkan hasil nilai $p$ yaitu 0.002 atau nilai $\mathrm{p}$ $<0,05$, dapat disimpulkan bahwa nilai $\mathrm{Ha}$ diterima dan Ho ditolak ini bearti ada pengaruh dalam menurunkan tingkat intensitas nyeri di SMK Negeri 1 Gerokgak.

\section{KESIMPULAN DAN SARAN}

\section{Simpulan}

Karakteristik responden berdasarkan usia ditemukan bahwa pada kelompok perlakuan dan kontrol menunjukkan responden termuda yaitu usia 15 dan tertua yaitu 17 dengan rata- rata umur responden pada kelompok perlakuan yaitu 15.88 dan pada kelompok kontrol adalah 15.76..

Tingkat intensitas nyeri dismenorea sebelum diberikan swiss ball exercise pada kelompok perlakuan di dapatkan intensitas nyeri yang paling banyak yaitu nyeri sedang dengan rata-rata 4,92 dan kelompok kontrol didapatkan intensitas nyeri yang lebih banyak yaitu nyeri sedang dengan nilai ratarata yaitu3,96. Setelah sesudah diberikan swiss ball exercise pada kelompok perlakuan intensitas nyeri lebih banyak yaitu nyeri ringan dengan nilai rata-rata 3,24 dan kelompok kontrol intensitas nyeri yang paling banyak yaitu nyeri sedang dengan nilai rata-rata yaitu 4.04

Berdasarkan uji analisa data dengan mengunakan uji independent T-test didapatkan nilaip value0,002 <0,05 dapat di katakan adanya pengaruh teknik swiss ball exercise yang signifikan terhadap peneurunan intensitas nyeri dismenorea di SMK Negeri 1 Gerokgak dengan

\section{Saran}


Penelitian ini diharapkan dapat menambah pengetahuan kepada para mahasiswa tentang pengaruh swiss ball exercise dalam menurunkan intensitas nyeri. Dapat digunakan sebagi masukan perawat dan tenaga kesehatan lainnya. Penelitian ini diharapkan dapat menambah wawasan serta pengetahuan mengenai swiss ball exercise dalam menurukan intensitas nyeri serta sebagai dasar ilmiah dalam melakukan penelitian.

\section{REFERENSI}

Anurogo, D \& Wulandari, A. 2011. Cara Jitu Mengatasi Nyeri Haid. Yogyakarta : Andi.

Kurniawati, Ade., dkk. 2016). Efektifitas Latihan Birth Ball terhadap Penurunan Nyeri persalinan Kala I Fase Aktif Pada Primigravida. Jornal Of Nursing And Midwifery. 5(1).

Kodir, E., Angliadi, L.S., \& Lolombulan, J.H. (2018). Pengaruh Latihan Core Strengthening Menggunakan Swiss Ball Menurunkan Intensitas Nyeri Dan Meningkatkan Kemampuan Fungsional Nyeri Punggung Bawah Nonspesifik Kronik. Jurnal Kedokteran Klinik, 2(1), 21-24.

Laila, Nur Najmi. (2011). Buku Pintar Menstruasi. Jogyakarta : Buku Biru.
Nursalam, (2015). Metodelogi Penelitian Ilmu Keperawatan. Jakarta: Salemba Medika.

Oktaviani, A., \& Lestari, U. (2017). Efektivitas William's Flexion Exercise 
Dalam Pengurangan Nyeri

Haid (Dismenorhea). Jurnal

Ilmiah Kebidanan, 8(1), 11.

Proverawati, A. \& Misaroh, S. (2010).

MENARCHE

(Menstrua

si pertama penuh makna). Edisi

Pertama. Yogyakarta : Graha

Ilmu.

Ratmawati, Y., Setiawan., \& Kunttono, H.P.

(2015). Pengaruh Latihan

Swiss Ball Terhadap

Peningkatan Flesibilitas Trunk

Pada Remaja Putri Usia 17-21

Tahun. Jurnal Terpadu Ilmu

Kesehatan, 4(1), 20-21. 